\title{
Preservation of Radial Vasomotor Functions Through the Anatomic Snuffbox: A Prospective Comparison with other Radial Accesses during Coronary Angiography
}

\author{
Mehmet Kis and Elton Soydan \\ Department of Cardiology, EGE University, Izmir, Turkey
}

\begin{abstract}
Objective: To compare radial vasomotor functions at three different access sites namely right, left main radial artery, and left distal radial (LDR) artery.

Study Design: Observational study.

Place and Duration of Study: Department of Cardiology, EGE University, Turkey, from September 2017 to February 2018.

Methodology: Forty-one patients scheduled for transradial elective coronary angiography and intervention were consecutively enrolled. Access site decision was left free to operators being blind of the study. Main radial vasomotor function measured through flow mediated vasodilation test was compared between other radial access sites on admission, 1 day and 2 months post-catheterisation.

Results: Five patients were intervened through the left main radial, whereas the LDR and the right main radial access were used in 17 and 19 patients respectively. In contrast to other radial access sites, LDR approach showed significantly less influenced vasomotor functions the day after the procedure. This feature continued to be preserved for two months of followup.

Conclusion: Left distal radial branch in the anatomic snuffbox is a reliable access in terms of vasomotor function preservation compared to conventional left and right radial artery accesses.
\end{abstract}

Key Words: Transradial access, Flow mediated vasodilatation, Endothelial function.6re6445.

How to cite this article: Kis M, Soydan E. Preservation of Radial Vasomotor Functions Through the Anatomic Snuffbox: A Prospective Comparison with other Radial Accesses during Coronary Angiography. J Coll Physicians Surg Pak 2020; 30(11):1121-1125.

\section{INTRODUCTION}

Coronary angiography (CAG) and percutaneous coronary intervention $(\mathrm{PCl})$ can be performed through femoral, brachial or radial arteries. Although the femoral approach has been the primary site formost operators, radial access route has gained increased popularity in $\mathrm{PCl}$ and revascularisation procedures after its first report by Campeau et al. ${ }^{1,2}$ Multiple studies have shown that transradial approach leads to less vascular complications, shorter hospital stay, and early mobilisation in comparison with the transfemoral route. ${ }^{3,4}$ However, radial artery occlusion (RAO), non-occlusive radial artery injury and radial artery spasm have been reported as important complications of this approach damaging the endothelial mediated vasomotor functions in the radial artery wall. ${ }^{5}$

Correspondence to: Dr. Mehmet Kış, Department of Cardiology, EGE University Izmir, Turkey

E-mail:drmehmet.kis@hotmail.com

Received: June 10, 2020; Revised: October 21, 2020;

Accepted: November 11, 2020

DOI: https://doi.org/10.29271/jcpsp.2020.11.1121
Such vascular interventions complicating the endothelium may preventfuture use of the radial artery as a graft, reuse of transradial route and fistula pathway for hemodialysis. Therefore, this study was conducted to find the most reliable radial access site in terms of endothelial mediated vasomotor function preservation measured through flow mediated vasodilation (FMD).

\section{METHODOLOGY}

Forty-one patients assigned for elective transradial coronary angiography between September 2017 and February 2018 were included in the study. It was designed as a prospective study with single-blind fasion where the operator was left blind and free for radial access site selection decision. Patients with no previous transradial intervention were consecutively enrolled. In contrast, patients with no palpable pulse of the radial artery or those with limited echogenicity of Doppler ultrasonographic examination were excluded from the study. Signed informed consent form was obtained from each patient participating in the study. The study was designed in accordance with the principles of the Declaration of Helsinki and got approval from the Ethics Committee of the Hospital.

Demographic features such as age, gender, height, weight, body mass index were recorded on admission. In the end of 
enrollment, there were 3 groups formed according to radial access site: left main radial group (5 patients), left distal radial (17 patients) and right main radial artery group (19 patients).

The main radial artery was examined $5 \mathrm{~cm}$ proximal to the styloidal protruberance with a 4.5-12 MHz linear array probe (GE Healthcare Vivid E9 4D Cardiovascular ultrasound system) in all patients. The systolic diameter of the radial artery was defined as the maximum diameter during systole and the maximum shrinkage of the vessel diameter during diastole concurrently tracked by the $\mathrm{R}$ wave onset in electrocardiography was set as the diastolic diameter.

The procedure was performed in a quiet room, at $25^{\circ} \mathrm{C}$ of room temperature. Patients were requested not to exersize and seize tea or coffee for at least 30 minutes before the procedure. They were left resting in a supine position for at least 5 minutes with 12 hours of fasting. After recording of basal diameters of the radial artery, the cuff was inflated until $220 \mathrm{mmHg}$ of pressure for five minutes to totally occlude the downstream blood perfusion of the relevant hand. Then the cuff was immediately deflated and the maximal diameter of the radial artery obtained by measuring the distance from the anterior wall intima to the posterior wall intima was recorded. Radial artery diameter and percentage change after deflation were recorded at $1^{\text {st }}, 2^{\text {nd }}$ and $3^{\text {rd }}$ minutes.

Diameter change percentages were calculated using the FMD formula (FMD $(\%)=[$ (diameter after reactive hyperemia-basal diameter) / basal diameter] x 100). In this way, radial vasomotor functions of the intervention arm were examined on admission, 24 hours and 2 months post catheterisation.

A hydrophilic radial sheath (6 French Prelude 170 Ease, Merit Medical) was used for coronary angiography, with a $4 \mathrm{~cm}$ long 21 gauge open needle used for puncturing into the radial artery. A local anesthetic containing $2 \%$ of prilocaine $(2 \mathrm{ml}$ ) was applied to the radial access area before puncture. In order to prevent vessel related spasm or occlusion, 2500 units of unfractionated heparin, 200 mcg nitrate and saline cocktail were administered to all patients. In case of intervention, heparin dose contemplated intravenously according to patient's body weight. Radial sheath was removed at procedure termination and early hemostasis was achieved by manual compression for 15 minutes. The slightly compressing bandage remained for 12 hours in order to provide complete hemostasis at the access site.

Categorical data were described using observed frequencies and percentages, and continuous variables were summarised by their mean, standard deviation, median and interquartile range (IQR) with statistical package (SPSS Inc., version 21.0, Chicago, IL, USA). The suitability of the numerical variables to normal distribution was examined by Shapiro-Wilk test. Chisquare test was used for categorical data. After the KruskalWallis test, pairwise comparisons were made with the Dunn test with Bonferroni correction. In all study, $p$ values $<0.05$ were considered to be statistically significant. In G Power 3.0.8
Program, power analysis based on variance analysis method was applied in repetitive measurements. The minimum sample size was found to be 30 to find the difference between times with alpha $=0.05$ error level, moderate effect size $f=0.25$ and $80 \%$ power.

\section{RESULTS}

Left main radial artery was used in $12.2 \%$ (5 patients), whereas the left distal and right main radial artery was used in $41.5 \%$ (17 patients) and 46.3\% (19 patients) respectively. The baseline characteristics of the study population are summarized in Table I. There was a young population (57.39 \pm 13.97 years) with a male predominance (70.7\%). Patients were overweight with mean body mass index (BMI) of $27.62 \pm 4.39 \mathrm{Kg} / \mathrm{m}^{2}$. Hypertension was the most common comorbid disease seen in the study population. There was no statistically significant difference between the three intervention groups in terms of hypertension, diabetes, hyperlipidemia and coronary artery disease.

Measurements of FMD on the intervention arm on the above-mentioned time periods were cautiously and precisely performed in the first, second and third minute of cuff deflation. The highest diameter and percentage diameter change were recorded during the first minute and accepted as reference measurements. Basal radial artery median (interquartile range) percentage diameter change in the left radial group was 12.00 (7.92), in the left distal radial group 13.64 (3.46), and 13.34 (6.07) in the right radial group. All these data were statistically similar in all three intervention groups ( $p=0.544$, Table II). The next day after the procedure, there was an increase in radial artery diameter of the intervention arm in all the three groups. Interestingly, diameter and percentage change were found significantly higher in the left distal group $(6.90 \mathrm{~mm}$ $; 5.46$ ) compared to the left radial and right radial group (3.23 $\mathrm{mm} ; 10.2$ and $3.28 \mathrm{~mm} ; 3.45)$ respectively ( $p=0.003$, Table II).

This suggested a higher preservation of the radial artery vasomotor functions through the left distal radial artery approach compared to the other conventional radial accesses.

Two months after the transradial coronary angiography, FMD test showed recovery of the diameter and percentage change close to preoperative values in all the three groups (Table II). Despite higher post ischemic diameter in the left distal radial group, no statistically significant difference was found between other groups at 2 months follow-up ( $p=0.064$ ). This could imply the restoration of endothelial functions in the radial artery at 2 months after the procedure. Regarding vessel complications, minor vessel-related bleeding defined as bleeding not necessitating blood transfusion or being life threating, was the most common complication with no significant difference ( $p=0.638$, Table III). Radial dopplerultrasonography confirmed no radial occlusion in the study population. One patient $(2.4 \%)$ had pseudoaneurysm on the right forearm radial artery site that was recovered by temporary ultrasonic probecompression(TableIII). 
Table I: Baseline characteristics of the study population according to access site.

\begin{tabular}{|c|c|c|c|c|c|}
\hline & $\begin{array}{l}\text { Left radial } \\
(n=5)\end{array}$ & $\begin{array}{l}\text { Left distal radial } \\
(n=17)\end{array}$ & $\begin{array}{l}\text { Right radial } \\
(n=19)\end{array}$ & $\begin{array}{c}\text { Total } \\
(n=41)\end{array}$ & p-value \\
\hline Age (years) & $58.4 \pm 22.6$ & $55.3 \pm 14.0$ & $59.0 \pm 11.8$ & $57.39 \pm 13.9$ & 0.729 \\
\hline Male, n (\%) & $4(80)$ & $12(70.6)$ & $13(68.4)$ & $29(70.7)$ & 0.487 \\
\hline BMI $\left(\mathrm{kg} / \mathrm{m}^{2}\right)$ & $27.54 \pm 3.44$ & $27.59 \pm 5.37$ & $27.66 \pm 3.82$ & $27.62 \pm 4.39$ & 0.998 \\
\hline Smoking, n (\%) & $2(40)$ & $6(35.3)$ & $5(26.3)$ & 13(31.7) & 0.555 \\
\hline Hypertension, n (\%) & $4(80)$ & $12(70.6)$ & 15(78.9) & $31(75.6)$ & 0.819 \\
\hline Diabetes, n (\%) & $2(40)$ & $8(47.1)$ & $6(31.6)$ & $16(39)$ & 0.636 \\
\hline Hyperlipidemia, n (\%) & $3(60)$ & $7(41.2)$ & $6(31.6)$ & 16(39) & 0.497 \\
\hline CAD, n (\%) & $2(40)$ & $6(35.3)$ & $6(31.6)$ & $14(34.1)$ & 0.932 \\
\hline $\mathrm{AF}, \mathrm{n}(\%)$ & $0(0)$ & $1(5.9)$ & $1(5.3)$ & $2(4.9)$ & 0.861 \\
\hline CKD, n (\%) & $1(20)$ & $1(5.9)$ & $0(0)$ & $2(4.9)$ & 0.176 \\
\hline COPD, n (\%) & $1(20)$ & $0(0)$ & $1(5.3)$ & $2(4.9)$ & 0.188 \\
\hline Thyroid disease, $\mathrm{n}(\%)$ & $0(0)$ & $0(0)$ & $3(15.8)$ & $3(7.3)$ & 0.154 \\
\hline Peripheral arterial disease, $\mathrm{n}(\%)$ & $0(0)$ & $1(5.9)$ & $1(5.3)$ & $2(4.9)$ & 0.861 \\
\hline
\end{tabular}

Table II: Diameter percentage change of the catheterized radial artery measured by flow mediated vasodilatation.

\begin{tabular}{|c|c|c|c|c|}
\hline Flow mediated dilatation & $\begin{array}{l}\text { Left radial group } \\
\qquad(n=5)\end{array}$ & $\begin{array}{l}\text { Left distal radial group } \\
\qquad(n=17)\end{array}$ & $\begin{array}{l}\text { Right radial group } \\
(n=19)\end{array}$ & p-value \\
\hline Before CAG & $12.00(7.92)$ & $13.64(3.46)$ & $13.34(6.07)$ & 0.544 \\
\hline After 24 hours & $3.23(10.2)$ & $6.90(5.46)$ & $3.28(3.45)$ & 0.003 \\
\hline After 2 months & $7.14(4.54)$ & $11.54(4.70)$ & $7.69(1.60)$ & 0.064 \\
\hline
\end{tabular}

Table III: Complications according to access site.

\begin{tabular}{|c|c|c|c|c|c|}
\hline Complication & $\begin{array}{l}\text { Left radial } \\
\text { artery } \\
(n=5)\end{array}$ & $\begin{array}{c}\text { Left distal radial } \\
\text { artery } \\
(\mathbf{n}=17)\end{array}$ & $\begin{array}{c}\text { Right radial } \\
\text { artery } \\
(n=19)\end{array}$ & $\begin{array}{c}\text { Total } \\
(n=41)\end{array}$ & p-value \\
\hline Minor bleeding, n (\%) & $1(20)$ & $1(5.9)$ & $2(10.5)$ & $4(9.8)$ & 0.638 \\
\hline Pseudoaneurysm, n (\%) & $0(0)$ & $0(0)$ & $1(5.3)$ & $1(2.4)$ & 0.552 \\
\hline Hematoma, n (\%) & $1(20)$ & $0(0)$ & $1(5.3)$ & $1(2.4)$ & 0.552 \\
\hline Radial artery thrombosis areas, n (\%) & $0(0)$ & $0(0)$ & $3(15.8)$ & $3(7.3)$ & 0.154 \\
\hline Radial spasm, n (\%) & $0(0)$ & $0(0)$ & $1(5.3)$ & $1(2.4)$ & 0.552 \\
\hline Occlusion & $0(0)$ & $0(0)$ & $0(0)$ & $0(0)$ & - \\
\hline
\end{tabular}

\section{DISCUSSION}

The use of radial artery access in coronary angiography has been increasing in recent years and has become the standard approach in multiple centers. Transradial intervention has been adopted as a preferred intervention site for diagnostic coronary catheterization since it is associated with lower rates of vascular complications, less major bleeding events, and less patient discomfort compared to transfemoral intervention. ${ }^{6-8}$ Vasoconstriction may occur in the vessel and rupture of the elastic lamina and media layer may occur, resulting in complications such as bleeding and hematoma. ${ }^{9} \mathrm{RAO}$, which is one of the most common complications, can be seen in $2.8 \%-11.7 \%$ of patients despite appropriate anticoagulation. ${ }^{10}$ Because of double forearm feeding, RAO is usually asymptomatic and is ignored, but sometimes paresthesia and distal ischemia may occur. ${ }^{11}$

A study supports a transient reduction in endothelium-depen- dent and independent vasodilatation of the radial artery after transradial CAG. ${ }^{12}$ The most important cause of this damage in the radial artery is the endothelial damage caused by the introduction of sheath and coronary catheter advancement inside. ${ }^{13,14}$ The clinical significance of this condition is that it makes it difficult to use the radial artery as a graft for future (coronary artery bypass graft) CABG, reuse as an access site for catheterization or as a shunt site for arterio-venous fistula for patients with chronic renal failure necessitating dialysis. ${ }^{15,16}$

In this study, the authors compared three different radial artery access sites used in for transradial CAG procedure with the goal to find the most reliable radial site in terms of radial artery vasomotor function preservation through FMD measurement. The same sheath was used in three different patient groups and homogeneity of demographic and comorbidity features was achieved. In addition to radial artery sheaths having a hydrophilic coating, agents such as dilti- 
azem, verapamil, nitroglycerin, papaverine, or adenosine administration can provide additional protection against radial artery spasm and or occlusion. ${ }^{17}$ Heparin is routinely administered to prevent thrombosis at the sheath insertion site. Nitroglycerin and heparin was administered to all the patients immediately after radial sheath implantation, and vessel- related complications were rarely seen. Use of verapamil has shown not significant protection in terms of radial artery spasm or pain, ${ }^{18}$ thus its routine administration was avoided. There was no major bleeding event due to the procedure in all the three intervention groups. Complications such as pseudoaneurysm and radial artery thrombosis area were seen more common in the right radial access compared to other access sites (2.4\% v.s $0 \%-0 \%, 15.8 \%$ v.s $0 \%-0 \%$ respectively). Right-handedness of the general population could be an important factor accounting for high vessel-related complication rates in the right radial intervention group, since patients continue to use their right hands after the procedure.

Although a small population, the low rate of vascular complications in the LDR access were thought to be linked to higher preservation of endothelial functions than the other access sites. The possible explanation of this preservation could lie in the fact that the distal radial artery is one of the distal branches of the main radial artery that the influence of the insertion of the radial sheath towards endothelium could be less than the introduction of it directly into the main radial artery.

FMD test is the most accepted non-invasive test reflecting arterial endothelial mediated vasomotor function. ${ }^{19}$ Tests based on drug delivery or requiring invasive procedures to evaluate endothelial functions were not performed due to side effect profiles and ethical issues. A study evaluating radial artery vasodilation functions on 20 patients and 20 volunteers showed improvement through FMD at 3 months after transradial CAG. ${ }^{20}$ Instead, the authors found an earlier improvement of FMD at 2 months post-catheterization. Awareness of endothelial function preservation course in the radial arteries could be a beneficial finding for the purpose of future re-catheterisation and or use as a graft for coronary surgery. Therefore, normalisation of radial endothelium, poses great importance. As our study population was homogenic in relation to demographic and comorbid diseases, endothelial function measurement through FMD showed high accuracy. This implied that independent of demographic and comorbidity features, the left distal radial access was more reliable than other accesses in terms of endothelial mediated vasomotor function preservation. As a result, the use of the left distal access in transradial coronary interventions seems to be advantageous and could be more protective against common vascular complications by less influencing the endothelium.

Although the relatively small sample size, the left distal radial artery group reached a significant statistical value, suggesting that the left distal access site was more reliable than other access sites. Randomised trials involving a higher number of patients are needed to better evaluate the relationship between vascular complications and radial endothelial function.

\section{CONCLUSION}

Left distal radial branch in the anatomic snuffbox is a reliable access for endothelial-mediated vasomotor function preservation and is linked to lower vessel-related complications compared to right and left conventional radial accesses.

Preservation of it poses benefits of left distal radial artery access for future re-catheterization, use of radial artery as a graft for coronary surgery and use as a shunt site for arteriovenous fistula for dialysis patients.

\section{DISCLOSURE:}

This study was presented as a poster presentation by the same authors at the European Society of Cardiology (ESC) congress held between 25-29 August 2018 in Munich, Germany. The summary of it was published in the European Heart Journal, with the reference: Skraqi E, Kis M, Akin M. P6371 Endothelial functions are preserved in left distal radial access coronary angiography, a prospective comparison with right and left forearm radial artery access site. European Heart Journal. 2018 Aug 1;39(suppl_1):ehy566-P6371.

\section{FUNDING:}

This study was not supported by any organisation.

\section{ETHICAL APPROVAL:}

Ethics Committee approval was received for this study from the EGE University Medicine Faculty (Decision No. 17-12.1/22).

\section{CONFLICT OF INTEREST:}

The authors declared no conflict of interest.

\section{PATIENTS' CONSENT:}

Written informed consents were obtained from all patients included in the study.

\section{AUTHORS' CONTRIBUTION:}

MK: Conception and design of the study, acquisition of data and drafting of manuscript.

ES: Analysis and interpretation of data and critical revision.

\section{REFERENCES}

1. Campeau L. Percutaneous radial artery approach for coronary angiography. Cathet CardiovasC Diagn 1989; 16(1):3-7. doi: 10.1002/ccd.1810160103.

2. Lee CW, Cho SC. The transradial approach for coronary intervention: more comfort, better outcome. Korean Circ J 2018; 48(8): 728-730. doi: 10.4070/kcj.2018.0118.

3. Valgimigli M, Gagnor A, Calabro P, Frigoli E, Leonardi S, Zaro 
T, et al. Radial versus ' femoral access in patients with acute coronary syndromes undergoing invasive management: a randomized multicentre trial. Lancet 2015; 385(9986):2465-76. doi: 10.1016/S0140-6736(15) 60292-6.

4. Mason PJ, Shah B, Tamis-Holland JE, Bittl JA, Cohen MG, Safirstein J, et al. An update on radial artery access and best practices for transradial coronary angiography and intervention in acute coronary syndrome: A scientific statement from the American Heart Association. Circ Cardiovasc Interv 2018; 11(9):e000035. doi: 10.1161/ HCV.0000000000 000035.

5. Kanei Y, Kwan T, Nakra NC, Liou M, Huang Y, Vales LL, et al. Transradial cardiac catheterization: a review of access site complications. Catheter Cardiovasc Interv 2011; 78(6): 840-6. doi: 10.1002/ccd.22978.

6. Collet JP, Thiele $H$, Barbato $E$, Barthélémy $O$, Bauersachs J, Bhatt DL, et al. 2020 ESC Guidelines for the management of acute coronary syndromes in patients presenting without persistent ST-segment elevation. Eur Heart J 2020; doi: 10.1093/eurheartj/ehaa575.

7. Salgado Fernández J, Calviño Santos R, Vázquez Rodríguez JM, Vázquez González N, Vázquez Rey E, Pérez Fernández R, et al. Transradial approach to coronary angiography and angioplasty: Initial experience and learning curve. Rev Esp Cardiol 2003; 56(2):152-9. doi: 10.1016/s0300-8932(03) 76839-0.

8. Anjum I, Khan MA, Aadil M, Faraz A, Farooqui M, Hashmi A. Transradial vs. Transfemoral approach in cardiac catheterization: A literature review. Cureus 2017; 9(6): e1309. doi: 10.7759/cureus.1309.

9. Sobolewski P, El Fray M. Cardiac catheterization: Consequences for the endothelium and potential for nanomedicine. Wiley Interdiscip Rev Nanomed Nanobiotechnol 2015; 7(3):458-73. doi: 10.1002/wnan. 1316.

10. Chen Y, Ke Z, Xiao J, Lin M, Huang X, Yan C, et al. Subcutaneous injection of nitroglycerin at the radial artery puncture site reduces the risk of early radial artery occlusion after transradial coronary catheterization: A randomised, placebo-controlled clinical trial. Circ Cardiovasc Interv 2018; 11(7):e006571.
11. Rashid M, Kwok CS, Pancholy S, Chugh S, Kedev SA, Bernat I, et al. Radial artery occlusion after transradial interventions: A systematic review and meta-analysis. J Am Heart Assoc 2016; 5(1):e002686. doi: 10.1161/JAHA. 115.002686.

12. Yan Z, Zhou Y, Zhao Y, Zhou Z, Yang S, Wang Z. Impact of transradial coronary procedures on radial artery function. Angiology 2014; 65(2):104-7. doi: 10.1177/00033197 13479650.

13. Ahmed F, Kakepoto N, Sandeelo IK. Radial artery occlusion following transradial coronary intervention. Pak Heart J 2019; 52(1):58-63.

14. Dawson EA, Rathore S, Cable NT, Wright DJ, Morris JL, Green DJ. Impact of introducer sheath coating on endothelial function in humans after transradial coronary procedures. Circ Cardiovasc Interv 2010; 3(2):148-56. doi: 10.1161/CIRCINTERVENTIONS.109.912022.

15. Wakeyama $T$, Ogawa $H$, lida $H$, Takaki A, Iwami T, Mochizuki $M$, et al. Intima-media thickening of the radial artery after transradial intervention. An intravascular ultrasound study. J Am Coll Cardiol 2003; 41:1109-14.

16. Wang S, Asif A. Transradial approach for cardiovascular interventions and its implications for hemodialysis vascular access. Semin Dial 2013; 26(3):E20-9. doi: 10.1111/ sdi.12044.

17. Kiemeneij F. Prevention and management of radial artery spasm. J Invasive Cardiol 2006; 18(4):159-60.

18. Hizoh I, Majoros Z, Major L, Gulyas Z, Szabo G, Kerecsen G, et al. Need for prophylactic application of verapamil in transradial coronary procedures: A randomised trial. The vitriol (is verapamil in trans radial interventions omittable?) trial. J Am Heart Assoc 2014; 3(2):e000588. doi: 10.1161/JAHA. 113.000588.

19. Kelm M. Flow-mediated dilatation in human circulation: Diagnostic and therapeutic aspects. Am J Physiol Heart Circ Physiol 2002; 282(1):H1-5. doi:10.1152/ajpheart. 2002. 282.1.H1.

20. Mitchell AJ, Mills NL, Newby DE, Cruden NLM. Radial artery vasomotor function following transradial cardiac catheterisation. Open Heart 2016; 3(2):e000443. doi: 10.1136/ openhrt-2016-000443. 